\title{
An Ethnography of Communication: Viva Voce in a Ghanaian University
}

\author{
Isaac Afful \\ Department of English, University of Cape Coast, Cape Coast, Ghana
}

Email address:

isaac.afful.@stu.ucc.edu.gh,iafful8@gmail.com

\section{To cite this article:}

Isaac Afful. An Ethnography of Communication: Viva Voce in a Ghanaian University. International Journal of Language and Linguistics. Vol. 5, No. 5, 2017, pp. 127-134. doi: 10.11648/j.ij11.20170505.12

Received: January 27, 2017; Accepted: May 27, 2017; Published: August 2, 2017

\begin{abstract}
Over the last few decades, researchers have shown much interest in written academic genres to the detriment of spoken academic genres, though spoken genres such as viva voces are quintessential to postgraduate studies and form part of the enculturation process of novice academics. Using the ethnography of communication approach as proposed by Dell Hymes and focusing on setting, participant and act sequence, this paper examined how these elements of ethnography are operative in three recordings of viva voces organised by a department of a university in Ghana. The study revealed that the setting, day, scene, and clothing of participants highlight the formal nature of viva voces, a finding which projects academics as businessminded individuals. Further, it was revealed that the participants of viva voces are usually academics who share similar beliefs and engage in practices cherished by the community of practice. The relationship between candidates and the assessors, was asymmetrical and power-laden as realized though the address terms and lexico-grammatical choices that the candidates make. Finally, the study revealed that the viva voces are organized into four schematic structures. The study makes key contributions to scholarship on postgraduate pedagogy, text construction, and ethnography of communication.
\end{abstract}

Keywords: Viva Voce, Ethnography of Communication, Oral Academic Genres, Postgraduate Studies, Discourse Community

\section{Introduction}

Academic genres are to a large extent, one of the most researched genres in discourse studies. They can be defined as genres that are primarily aimed at researching, producing and evaluating knowledge. Such genres are governed by norms accepted by members of the academic discourse community such as professors, lecturers, researchers and graduate students. A discourse community refers to a group of people joined together by the particular ways in which they use language, such people have similar beliefs, values and attitudes towards how language is used. Academic genres can be written or spoken. Written academic genres include the research article, conference papers and journals. Spoken academic genres include inaugural lectures, seminar presentations, round table discussions and viva voces. As ESP casts an increasingly larger net over the linguistic demands made of students in particular academic fields, its focus has likewise widened to include a greater variety of genres [28]. The term viva voce, as used in this paper, is coterminous with the terms, thesis defence, thesis presentation or oral thesis examination. As Bridges [4] as cited in Markulis and Strang [14] notes, viva voces like other oral examinations aims at providing students with the opportunity to develop and demonstrate oral communication ability as well as helping students develop explanatory skills, powers of persuasion, oral poise and self-confidence.

Over the last few decades, researchers have shown much interest in written academic genres to the detriment of studies in oral academic genres. The few studies on oral academic discourse have focused on the lectures [21; 5], seminars [28] and conference presentations $[6 ; 22]$. There appears to be a dearth of empirical studies on postgraduate thesis defence especially within Africa. This study attempts to fill in the lacuna by investigating how setting, participants and the act sequence as elements of Dell Hymes' Ethnography of Communication are manifested in viva voces organized by a department in a Ghanaian university.

This study aims at teasing out how Setting, Participant 
and Act Sequence as elements of Hymes' ethnography of speaking, are operative in viva voces organized by the Department of English of the University of Cape Coast, taking into consideration the norms and practices of the speech community. In what follows, I present a review of studies related to the present study. This is done focusing on theoretical framework, conceptual notions and empirical studies that underpin the present study. The review of related literature is organized in two-folds. First, I present the theoretical lens of the study by teasing out the rationale, motivation and tenets of the ethnography of speaking as an approach in sociolinguistic study. This is done to provide an appropriate context to discuss the data gathered. Next, I sketch a vignette of the extant literature in order to provide a conceptual context for the study. Next, I describe the methodological procedure adopted for the data collection and this is follow by the results and a detailed analysis and discussion of the data, whereupon I will conclude with a summary and implications for future research.

\section{Theoretical Framework}

I draw on the Ethnography of Speaking framework as propounded by Dell Hymes [11] and its related concepts of speech community and community of practice. The ethnography of speaking is both an analytical and theoretical framework that brings to bear the relationship that exists between language, culture and society. It sees every speech event as arising out of, and in response to, a number of factors which are exhibited in the production of speech. Historically, the Ethnography of Speaking is part of linguistic anthropology, arising out of the traditional anthropological and is concerned with the interrelationships among language, culture, and society. Its focus, however, is upon aspects of interrelationship that are missing from both grammars and ethnographies taken separately or analytically combined [3]. It aims at investigating the use of language in the conduct of social life. Dell Hymes proposed this framework to account for the situations and uses, the patterns and functions of speaking as an activity in its own right. In other words, one of his goals was to create a theory that helped researchers study language use in specific contexts (at that time, some researchers in the field of Linguistics were trying to study language by itself, removed from the times and places people talked). Hymes [11] argues that by looking at how people actually use language, patterns could be discovered that otherwise would not be by just looking at the words themselves. He proposed the expression "Ethnography of Speaking" to look at how people use speech to communicate in a speech community but later on, the approach was changed to be known as "Ethnography of communication to include other symbolic means of expression (such as written and computer-mediated modes of communication). As typical of ethnographical studies, Hymes asserts that it is necessary for a researcher to examine one of the following six basic units in studying the communication conduct of a particular culture: speech community, speech event, speech situation, communicative act, communicative style and ways of speaking.

Hymes then proposed a research tool that can help researchers in analyzing language in, for instance, a speech community. These research variables or elements are summarized in the acronym, SPEAKING. "S" denotes the setting and scene of the communicative event. "P" stands for the participants involved in the speech event and more importantly, their roles and the relationships between the participants. "E" represents the ends, purposes or goals of the communicative event while " $\mathrm{A}$ " represents the act sequence taking into consideration the form and content of the speech event. The " $K$ " element designates the key or tone of the speech event whereas the "I" element represents the instrumentality or the channel through which communication flow can be investigated. The " $N$ " element denotes the norms of interaction and norms of interpretation or the rules guiding the talk and interpretation to bring out meaning and the final element, "G" represents the genre (traditional speech genres) embedded in the speech event.

One key element worth mentioning in Hymes' ethnography of speaking is the speech community. Hymes [11] explains the concept of a speech community as people who share "rules" for when and how to speak. He further adds that every member of a speech community should share at least one "way of speaking" with others and should understand the meanings of what other members in the speech community say. Two other inter-related terms to the concept of speech community are discourse community and community of practice. The three terms as Afful [2] notes, may not be extremely polarized or markedly different from one another [2]. A community of practice, according to Eckert and McConnell-Ginet [7] as cited in Afful [2] refers to an aggregate of people who come together around a mutual engagement in some common endeavor. Ways of doings, ways of talking, beliefs, values, power relations - in short, practices emerge in the course of their joint activity around that endeavor. Broadly speaking communities of practice (hereafter CoP) can be defined, in part, as a process of social learning that occurs when people who have a common interest in a subject or area collaborate over an extended period of time, sharing ideas and strategies, determine solutions, and build innovations. Early proponents of the term "community of practice" are Jean Lave and Etienne Wenger [12]. Wenger [29], for instance, defines CoP as groups of people who share a concern or a passion for something they do and learn how to do it better as they interact regularly. For them, three main components underpin the concept of CoP, namely: the domain, the community and the practice. In other words, a CoP has an identity defined by a shared domain of interest rather than a mere network of friends, constitute a group of people who demonstrate communality by sharing, interacting and engaging each other on daily basis and members of a CoP are practitioners who develop a shared repertoire of resources through a variety of 
methods which include problem solving, coordination and synergy, visiting other members, mapping knowledge and identifying gaps.

In this light, postgraduate students constitute a community of practice in the sense that they engage in the norms and practices of the academic discourse community and one of these practices in the tertiary institutions is the thesis defence or the viva voce. They also constitute a speech community in the sense that they draw on existing linguistic rules within their community of practice and adhere to the rules regarding the use of speech in thesis defence.

\subsection{Thesis Writing and Defence in Applied Linguistics}

Like written postgraduate thesis, thesis defence is very quintessential in graduate research education and it provides evidence of advanced academic literacy in several universities worldwide [1]. A successful thesis defence marks the terminal point that marks a successful completion of research work in most universities. In other words, a masters' or doctoral thesis represents the peak of a student's academic attainment [1]. Etymologically, the term, "Viva voce" is a Latin expression used in Catholic seminary education to refer to oral examinations. Literally, it means "Living voice" and was used to complement written examinations [14]. The term, thesis, according to Afful [1:135] can be broadly thought of "as a report of findings of higher research study and represents substantial subject knowledge gained as well as the cultural, professional norms, and practices acquired during years of socialisation in a discipline. He further adds that a thesis is usually written to perform at least one or all of the following functions: to solve a problem, to prove something, to contribute to knowledge and understanding of a particular topic, to demonstrate particular skills, to convince a reader or to gain admission to a particular area of study. Thesis presentations are also assessed based on their uniqueness, freshness of ideas, evaluation of their contribution to the knowledge enterprise and publishability [Mullins \& Kiley, 17 as cited in Afful, 1]. The thesis defense like the graduate seminar, is a constituent of the discourse category which the genre doyen, John Swales $(24: 177)$ had termed, "other research-process genres".

\subsection{Studies on Oral Academic Discourse}

The literature on academic discourse reveals that many studies have investigated written genres especially the research article, following the line of the genre doyen, John Swales. A thorough classification of oral academic genres according to criteria of purpose, rather than to interaction between speaker and listener, has been provided by Fortanet [8], who distinguishes three main levels of academic genres: classroom, institutional and research genres. The first level of academic genres (classroom genres) has a clear pedagogical instructional aim, whereas the other two, although mainly research-oriented, can easily be instructional when approached from an applied corpus linguistics perspective.
The classification of oral academic genres as given by Fortanet [8] is presented in Figure 1 below:

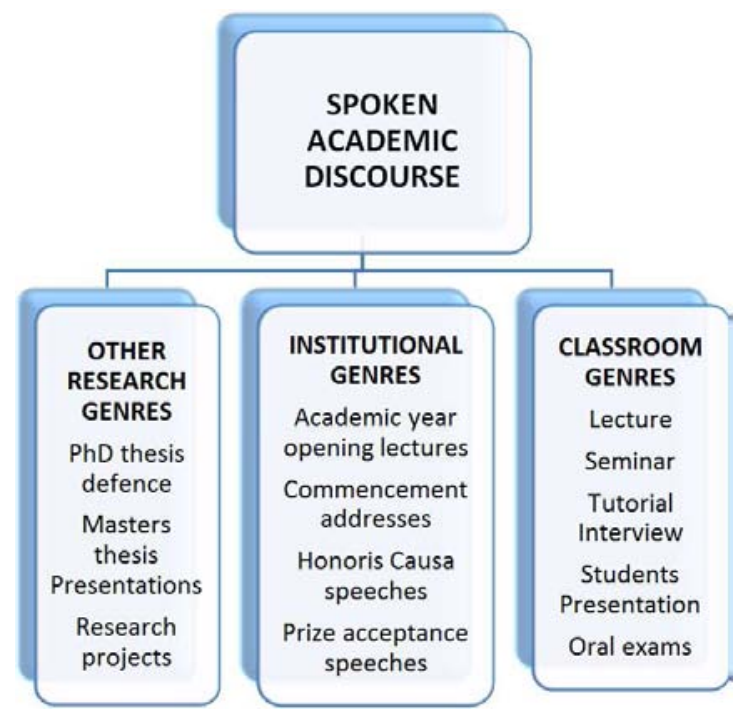

Figure 1. Classification of Oral Academic Genres (Fortanet, 2005).

Fortanet [8] classifies oral academic genres into three: Classroom Genres, Institutional Genres and Research Genres. The classroom genres include lectures, seminars, tutorials and presentations while the institutional genres comprise academic year opening lectures, commencement addresses and honoris causa speeches. The research genres also include $\mathrm{PhD}$ thesis defense, Master's thesis defense and research projects. Such a classification seems to suggest that lectures and seminars are not research genres. The literature indicates that relatively few studies have been conducted on oral academic discourse (hereafter, OAD). Most studies on OADs have focused on classroom discourse especially on the postgraduate lecture [21; 5]. Csomay [5], for instance, investigated the linguistic features of academic lectures in comparison to face-to-face conversation and academic prose. His study revealed that academic lectures exhibit a high informational load represented by the dominance of nominals, the use of existential "there", inversions and pseudo-cleft structures. Within the lecture genre, scholars have also explored the genre employing various analytical frameworks. These include Corpus Linguistics: (Biber, 2003; Biber et al, 2008; Carmen, 2009; Wenger, Cotes \& HerbelEisenmann, 2010), Genre analysis [13], Systemic Functional Linguistics [26] and Multimodality [25]. Studies such as those of Dubois [6] have focused on conference presentations and have investigated variables such as information structure, style-shifting and generic structure. Dubois' study, for instance, presents a generic structure of biomedical conference presentations and concludes that such presentations have are structures as: Introduction, Body and Termination moves. She argues that, the introductory move, like the termination move, is either listener-oriented or content-oriented while the body embodies steps such as the situation, event and commentary. Again, some studies on OAD such as that of Mercer [16] have investigated 
classroom talks in general by focusing OAD socializations and code switching. Concerning studies on viva, Mercer found out that there are less empirical studies on viva voces. However, some theoretical studies such as that of Markulis and Stang [14] discusses the history and rationale for using oral exams, and provides a model for instructors of upper level business courses to augment their course pedagogy by using the oral exam format. The paper concludes by offering a set of guidelines for implementing the oral exam methodology in selected upper-level business courses.

The review indicates that there appear to be a dearth or paucity of empirical studies on OAD especially on a viva voces, compared to other written academic genres. This study thus attempts to fill in the lacuna by employing an ethnographic approach to investigate viva voces in a department in an African setting.

\section{Methodology}

The study employed a qualitative research design. Qualitative analysis, as Reinard [20] notes, describes observations in predominantly non-numerical terms and emphasizes description or interpretation of communication events. It is appropriate to use the qualitative research design for this study because this study concerns itself with the socio-human relationships, and the nature of interactions between participants in communicative events. As an analytical description, the study is not supported in the analysis by quantitative material but by details or examples of ethno-linguistic behavior.

The site for the study was the Faculty of Arts Conference Room, University of Cape Coast. Here, three sessions of masters' thesis defence were being organized for candidates from the Department of English, who have successfully passed their written theses. The Faculty of Arts is the mother faculty of the University of Cape Coast [Osei Kwarteng, Boadi-Siaw \& Dwarko, 18]. The Faculty hosts ten departments: English, French, Ghanaian Language, Music, Theatre Studies, African studies, Religion and Human Values, History and Classics and Philosophy and it is well noted for its prowess in research in the Humanities and related disciplines. This site was chosen for the study because members of the Faculty of Arts also constitute a speech community as Hymes notes. The members of the faculty have similar attitudes, beliefs and norms as regards the use of speech as a communicative tool in the academic context. Again, the site was chosen on grounds of its proximity to the researcher.

The source of information for the present study was obtained from three main sources. First, the theoretical papers on Dell Hymes' ethnography of communication and empirical materials on oral academic genres and vivas were obtained from secondary sources which have been duly cited. Second, the data for the study comprised a transcription of three different recordings of the viva voce organized by the Department of English, University of Cape Coast. Three sessions of the thesis defence were recorded for the study.
During the transcription, the pseudo-names of the participants in the discourse were used. This was done paying attention to the ethical considerations that guide academic researches of this nature. Prior to the recording, the formal consent of the three candidates were sought. The researcher, having explained to them the rationale of the study and echoing the fact that it was purely for academic purpose, was granted permission by the participants. The first recording lasted fifty-one minutes, fifty-four seconds while the second and third recordings lasted fifty-two minutes, thirty-eight seconds and fifty-three minutes, eleven seconds respectively. After the recording, the data was coded using the open coding system. The main function of open coding, in the words of Punch [19: 210], is "to expose theoretical possibilities in the data". This process was used to tease out identifiable elements of Hymes model in order to find conceptual categories in the data. Finally, the research was supported by my own intuitive knowledge on thesis defence as a member of the academic discourse community.

As earlier indicated, the research employed an ethnographic of speaking approach to sociolinguistic studies. This approach is both an interpretive and analytical framework that attempts to explain how language is used in a context. As an interpretive framework, it helps the sociolinguist to understand and interpret how language is used in the specific context. As an analytical framework, the ethnography of speaking, (more recently, ethnography of communication), helps the sociolinguist to analyse data from a particular socio-cultural context. The data gathered was analysed paying attention to some of the elements that Hymes proposes for interactants to use in achieving communicative competence. These tools are mnemonically summarized in the acronym, SPEAKING, where S represents Setting, $\mathrm{P}$ for Participants, E for End, A for Act sequence, K for Key, I for Instrumentalities, $\mathrm{N}$ for norms and $\mathrm{G}$ for genre. The data was also analysed paying attention to the stylistic features that characterize academic writing in academic domains.

The choice for that ethnography of speaking approach as proposed by Hymes is appropriate because a viva voce is a genre of academic communication, and a social act that makes use of the elements embodied in Hymes' SPEAKING model. Again, an ethnographic research, the use of this model helps the researcher to understand particular social situations, events and roles and it also serves as an investigative process in which the researcher makes sense of a social phenomenon by contrasting, comparing, replicating, cataloguing and classifying objects of the study. The study subscribes to the view that various factors influence the language choice a speaker makes in order to make a communicative event a successful one.

\section{Results and Discussions}

The considerations of Setting, Participant, Act and Norms of interaction are especially crucial and worthy to be discussed in this section. These elements are selected for 
discussion since I find them interesting and core to the organisation of viva voces. The choice is also made due to space constraints.

\subsection{Setting}

The first element in Hymes' model is the Setting. This also embodies the scene of the speech event. The setting, on one hand, refers to the physical circumstances in which the speech event takes place. According to Gumperz and Hymes $[9$, p. 60], setting is defined as 'the time and place of a speech event and, in general, to the physical circumstances.' Thus, it embodies the time and place of the event. Scene, on the other hand, refers to the abstract psychological setting, or the cultural definition of the occasion [Wardhaugh, 27 as cited in Sarfo, 23].

The data indicates that the setting of viva voces is generally formal. Viva voces are usually organized in conference rooms, seminar rooms or in an enclosed place. Because of the formal nature of the interaction and the setting for the thesis defence, people who attend such programs are formally dressed and they adhere to the norms governing the examination. The scene of viva voces is that of an examination. The viva voce, as already indicated, is examinable or assessed. The candidate is expected to pass the exam before he is awarded the postgraduate degree he has been working for. It is also a learning process, as participants of the communicative event take notes to broaden their horizon. At such gatherings, the chairman for the occasion spells out the requirements that those postgraduate students who are yet to complete their thesis defence should meet. The extract below illustrates this assertion:

\section{Extract 1}

Chairman: Once again we are here to give opportunity to our colleagues who have worked so hard to get to this point. I'd always (.) like to remind all of us what graduate training entails. It involves first, the course work, you must ensure you pass and obtain a minimum (.) of 2.5 before you move on to the research. You have to engage us in the research proposal. If you don't pass it, you don't move forward. Now after passing the research proposal, you then start the research which culminates in the dissertation or thesis. YOU MUST PASS THAT ONE TOO. If don't pass the thesis, we cannot appear here for the viva. In other words, both assessors. should indicate that you have passed (.) it only when both have confirmed that the thesis has been passed that we organize a viva (.) for you. This means that our three students (.) have their thesis passed. Both assessors have passed them and that's why we are here.

Conscious of the nature of the setting, the candidates for the oral examination are very careful in what lexicogrammatical choices they make in communication. These indicators of formality are discussed in the Act sequence section of the analysis. The general organisation of the setting, in terms of sitting arrangement, attire worn by participants also contribute to the formal nature of the entire examination.

The formal nature of the place for the thesis defence is suggestive that academics are serious-minded and businessminded individuals. Thus, since the nature of the discourse to be undertaken is formal, a formal setting is chosen to suit the occasion. As regards the time for the thesis defence, the data revealed that thesis defenses are organized in the mid mornings, at about 9:00 GMT. Perhaps, this is due to the fact that by such times, most of the academics and other invitees have reported to begin the day's activities and so, they are able to make it to the program. Again, it is possible that organizing viva voces in the mornings is connotative to the freshness of ideas that is expected to be shared with the freshness of the new day. In other words, one could argue that the candidate and other academics who are present during the viva voces are not much burdened with work and so, the candidate is expected to milk out fresh discoveries to his audience.

\subsection{Participants}

The "P" element in Dell Hymes' SPEAKING model represents the participants in the communicative process and more importantly, the social role or relationships that exist among the participants. From the study, it was revealed that participants of viva voces are mostly academics. They include senior members and junior members of the speech community. The senior members include professors, deans, and heads of departments, senior lecturers, and assessors. The junior members include postgraduate students, senior research assistants, principal research assistants, teaching assistants and undergraduates who are usually final year students. Also, it was found that some supporting staff members of the speech community were present to offer secretarial and ushering services. It is also observed that attendees to the viva voce are members whose fields of study or discipline are related to the topic being discussed.

It is seen from the data that almost all the participants present in the three episodes of the thesis defense were from the Department of English and the Department of Ghanaian Languages and Linguistics. Thus, academics from Biological Sciences, Physical Sciences or Medical Sciences were absent from the viva presentations. What accounts for their absence is that such members, though such academics are members of the academic community in general, they do not constitute members of the speech community.

It is also observed that multiple identities are assigned to and constructed by the participants during viva voces. To begin with, the chairman performs the role as a convener of the meeting and he spells out the norms governing the examination. In the data under discussion, the chairman was a senior lecturer and a head of department within the faculty. The chairman, generally, ensures that the examination is conducted in a fair and academically rigorous manner. $\mathrm{He}$ also ensures that the candidate has the opportunity to defend the thesis and respond to all questions posed by the examiners and that the questions posed by the examiners are done fairly and professionally.

The chairman again directs the affairs of the communicative exchange or regulates turn-taking. That is, he 
decides which of the panel members should take his turn at for a specific time and allocates some time for questions. The extract below buttresses this point:

\section{Extract 2}

Chairman: Well, well. that was Mr. Smith. Umm (.) perhaps, I should begin thinking of being speaker of Parliament (All laugh). Anyway, ermm, we'd now invite panel members to interact with the candidate and the first to do this is the Dean, Prof. Myers.

Chairman: I now invite Dr. Bediako. Yea, Dr. Bediako?

The presence of assessors and external supervisors is also worthy to note. These functioned as gatekeepers in the knowledge enterprise. As experts in the discourse community, they ensured that what the candidate - a novice researcher - presents, concords with what is recognized as knowledge and with the accepted practices in the research in the Humanities. The junior members present also perform key roles during the viva. The postgraduate students are present to add to their knowledge and take note of the comments the panel members made on the presentations from the candidates. Some of the students, especially those who were course mates of the candidate presenting, were also present to cheer the candidate on to victory.

With regard to the relationships that exist among the participants, it was revealed that the relationship between the candidate and the assessors was asymmetrical. That the relationship between the participants is vertical is not surprising, given the formal nature of the interaction. The candidate always addresses the panel members by their titles rather than by their names. From one of the episodes recorded, it was seen that though the chairman for the occasion was an internal supervisor for the candidate and that their supervisory sessions were less formal, during the thesis defense, the candidate addressed his supervisor and chairman for the event with his (the Chairman's) full title. The following extract illustrates this assertion:

Extract 3:

Candidate - Thank you very much, Mr. Chairman. Mr. Chairman, panel members, colleague students, ladies and gentlemen, good morning. Mr. Chairman, I appear before this house for a presentation on my study which examined how political actors use language on campaign platforms for their political purposes.

Unsurprisingly, other linguistic markers such as the use of complex sentences, polysyllabic words, and passivisation (which are typical of formal academic discourse) were also dominant in the texts.

\subsection{Act Sequence}

The next element to be discussed is the Act Sequence. This represents the content and form of the discourse: the precise word used in the speech event, how they are used, and the relationship of what is said to be the actual topic at hand [Wardhaugh, 27 as cited in Sarfo, 23]. The data revealed that thesis defence process is organized into the following four sub-rhetorical structures or what Swales [24] calls moves: Introduction, Presentation of thesis, Defence of thesis,
Conclusion. Due to space constraints, three of these moves Introduction, Presentation of thesis and concluding move are discussed here:

\subsubsection{Introduction}

The introductory move of viva voces contained plenary remarks usually made by the chairman and it attempts at exposing or giving those present an overview of the oral examination. This move were realized through steps (see Swales, 24), which include welcoming of members, stating the purpose of gathering, stating rules and norms governing the examination and introducing core participants. These steps are given evidence in the following extract:

\section{Extract 4}

Chairman: Once again we are here to give opportunity to our colleagues who have worked so hard to get to this point. I'd always like to remind all of us what graduate training entails. It involves first, the course work, which you must ensure you pass and obtain a minimum of 2.5 before you move on to the research. You have to engage us in the research proposal. If you don't pass it, you don't move forward. Now after passing the set proposal, you then start the research which culminates in dissertation or thesis. You must pass that one too. If you don 't pass the thesis, we cannot appear here for the viva. In other words, both assessors should indicate that you have passed it (.) only when both have confirmed that the thesis has been passed that we organize a viva for you. This means that our three students have their thesis passed. Both assessors have passed them and that's why we are here. Now the next thing that I want us to take note of is the rules. To our presenters, the students, you have a maximum of 15 minutes to make your presentation and note that it's a presentation that you are making. This is the Department of English, we expect that you make a presentation. After the presentation, panel members would engage you to find out whether you actually did the work or it was somebody else who did it. At this point, I would like to introduce the panel members. For the first presenter who happens to be Mr. Smith, the panel members are Dr. Seidu Maiga, Prof. Dorinda Myers., Dr. Kokuvi, can we ask you to. the one who is supposed to. is not here; it's 10:00 and we need to start. So if you don't mind can you. So, Dr. Kokuvi, sorry for this late erm., then we have Dr. Philip Garbah and then we have Dr. Ayerh. These are the panel members. I think we are set! And I see the students also set, very anxious to deliver before the house. Mr. Smith, I think if you are ready, we are ready. Go ahead. [Viva 2]

However, there were some variations in the steps in all three data sets. In general, it was found that the introductory move was aimed at calming down the tensed atmosphere that is typical of such academic examinations.

\subsubsection{Presentation of Thesis}

The next move of the viva voce was the presentation of the postgraduate thesis. Here, the candidate demonstrates his presentation skills as he effectively employs the written, spoken and visual modes of communication (usually, power point presentations) to persuade his audience. The 
presentation was organized coherently following the IMRDC model. This finding corroborates with that of Mariotti [15] whose study on conference presentation reveals that CPs tend to reproduce the Introduction, Materials and Methodology, Results, Discussion and Conclusion pattern as observed in research articles. The candidates also paid attention to the accepted norms regarding the use of language in the speech community. That is to say, values such as intertextuality, hedging, explicitness of ideas, criticality, the use of appropriate vocabulary and cohesion and coherence were adhered to. The extract below illustrates some of these features of academic discourse.

Extract 5

Candidate 2: The background to the study. English is taught in one form or the other from elementary school upwards and it is hoped that by the end of one's second cycle of education, one would be able to connect new knowledge with previous knowledge. David Crystal. Sorry. Essay writing is one of the ways used to express this connectedness. Crystal (1997). states that writing paragraphs or essays in English is regarded as an important skill for anyone to organise the reality of the world and express one's feelings and thoughts to others in Englishspeaking social setting both formally and informally. In the academic context, writing. writing needs to be comprehensive and readable. Hence, the need for cohesion in writing. One may ask, What is cohesion? Halliday and Hassan (1976). according to Halliday\& Hassan (1976), cohesion is a semantic concept (.) and it refers to the relations of meaning that exist within a text and defines it as a text. Thus, cohesion occurs when the interpretation of some elements in the discourse on. on that. on the other. Researchers have given considerable attention to how second language learners write and what problems they usually encounter in their writing. For instance, Afful (2005), Appiah (2002) and Adika (2009) brought to light some of the problems tertiary education students face in organising their essays. One of the findings that runs through the studies was the inadequate use of linking devices to organize their essays and this is what motivated this study. However, this study is based. is based on the. is based on the senior high school student essays since it's from the SHS that students enter universities or tertiary educational schools. Although many researchers such as Olateju (2006), MinnowMensah (2005), Karasi (1994) Johnson (1990) just to mention a few have explored cohesion in students writing, only few of them have explored cohesive devices in text-types. The following research questions guided the study: one, what is the range of grammatical cohesive devices in students' narrative and argumentative essays? Two, what are the similarities and differences between the grammatical cohesive devices used in the students' narrative and argumentative essays? Three, what is the relationship between the grammatical cohesive devices and the quality of writing in the narrative and argumentative essays [Viva 3].

As regards intertextuality, the candidate drew on previous studies such as those of Halliday and Hassan (1976), Crystal (1997), Afful (2005), and Olateju (2006) to build upon his arguments. This feature is most cherished by academics and it portrays academics as humble and, well-read individuals. Candidates also used appropriate vocabularies which were mostly evidenced in their use of lexical chunks such as "The following research questions guided the study." and "The study revealed that. Hedges (mostly lexical verbs) such as appear, believe, seem, and perhaps were also dominating the data set. Again, cohesion and coherence of arguments presented in the thesis was also common in all the three samples. Given that the purpose of viva voces was persuasive in general, the candidates made use of various transitional or pragmatic markers such as "Now my major findings. (A)", "For my methodology (B)" and deictic expressions to make their arguments coherent and listener-friendly.

\subsubsection{Conclusion}

This move signaled the end of the viva voce. It corresponds to Dubois' [6] termination move. The move comprised steps such as adjournment of sitting and declaration of examination results. After the thesis presentation and deliberations, the sitting is briefly adjourned and all present (but the panel members, the chairman and other senior members) are asked to leave the examination room, so as to enable the panel to assess the candidate's performance. After the panel arrives at a decision, they reconstitute the meeting and pass a verdict on the candidate's performance: whether the candidate has passed or failed. Candidates who failed (as it was the case of the first presenter) are asked to re-appear before the panel at a later date while those who pass are congratulated and are asked to make corrections suggested by panel members in their final submission of the thesis. As Hymes notes, these norms of interaction and interpretation are cherished by the speech community and they are necessary to make a speech event successful. Some speech act such as congratulations, advice and cautions were also evident in the data set.

\section{Conclusion, Findings and Implications}

Employing the ethnography of speaking approach as postulated by Dell Hymes [10,11], this study examined viva voces organized by a department in a Ghanaian university, with a view to finding out how setting, participants and act sequence are operative in masters' theses defence. Three sessions of the viva voces were recorded and transcribed for the analysis. First, the analysis revealed that the choice of the setting, day, context of situation (scene), the clothing of participants and arrangement of seats highlight to formal nature of viva voces, a finding which projects academics as business-minded individuals. Second, it was revealed that the participants of viva voces are usually academics who share similar beliefs and engage in practices cherished by the speech community. The relationship between candidates and the assessors, the data revealed, was asymmetrical and this was realized though the formal address system employed and lexico-grammatical choices that the candidates make to suit the formal nature of interaction. This finding is also suggestive of some power relations that exist among the participants. Finally, the study revealed that in terms 
of form, the viva voce is organized into four moves Introductory move, Presentation of thesis, Defence of thesis, Concluding move. The study also highlighted some of the stylistic features that were evident during the presentation of the thesis. Some of these norms cherished by the academic discourse community include intertextuality, hedging, coherence of ideas and appropriate vocabulary choices.

The study makes a significant contribution to postgraduate writing. It contributes to the literature on academic genres by focusing on a relatively less researched spoken genre - the viva voce. It also has pedagogical implications for thesis supervisors, thesis assessors and postgraduate students. It is significant for text construction as far as the discussion of the act sequence (form and content) of viva voces and the generic structure of the entire viva voce are concerned. Finally, the study makes a vital contribution to the ethnography of speaking (now, ethnography of communication) as an analytical tool for spoken academic genres.

\section{References}

[1] Afful, J. B. A. (2012). Postgraduate thesis writing in the Humanities: Advanced academic literacy and role of Applied Linguistics. In D. F Edu-Buandoh \& A. B. Appartaim (Eds). Between language and literature: A festschrift for Prof. K. Edu Yankson (pp. 133-147). University of Cape Coast Printing Press.

[2] Afful, J. B. A. (2007). Address forms and the construction of multiple identities among university students in Ghana. Sociolinguistic Studies, 1(3), 461-481.

[3] Bauman, R., \& Sherzer, J. (1975). The ethnography of speaking. Annual Reviews, 4, 95-119. Sourced from: www.annualreviews.org/aronline. Accessed on 12th May, 2017.

[4] Bridges, S. (1999). Oral case exams in marketing: Enhancing and evaluating communication and problem-solving skills. Marketing Education Review, 9(3), 27-35.

[5] Csomay, E. (2001). Academic lectures: An interface of an oral and literate continuum. Nov ELTy Journal, 7(3), 1-10.

[6] Dubois, B. (1980). The genre and structure of biaomedical speeches, Forum Linguisticum, 5, 140-168.

[7] Eckert, P., \& McConnell-Ginet, P. (1998). Communities of practice: Where language, gender and power all live. In J. Coates (Ed.) Language and gender: A reader (pp. 484-494). Oxford: Blackwell.

[8] Fortanet, I. (2005). Honoriscausa speeches: An approach to structure. Discourse Processes, 7(1), 31-51.

[9] Gumperz, J., \& Hymes, D. (1972a) Directions in Sociolinguistics - The Ethnography of Communication. USA, Holt, Rinehart \& Winston.

[10] Hymes, D. (1986). Models of the interaction of language and social life. In J. Gumperz \& D. Hymes (Eds.), Directions in Sociolinguistics: The Ethnography of Communication. Oxford, New York: Basil Blackwell. (pp. 35-71). New York: Holt, Rinehart and Winston.

[11] Hymes, D. (1974). Ways of speaking. In R. Bauman \& J. Sherzer (Eds.) Explorations in the Ethnography of Speaking. (pp. 433-451). London: Cambridge University Press.

[12] Lave, J., \& Wenger, E. (1991). Situated learning: Legitimate peripheral participation. Cambridge University Press, Cambridge.

[13] Lee, J. (2011). A genre analysis of second language classroom discourse: Exploring the rhetorical, linguistic, and contextual dimensions of language lessons. Applied Linguistics and English as a Second Language Dissertations. Paper 20.

[14] Markulis, L. \& Strang, G. (2008). Viva voce: Oral exams as a teaching \& learning experience. Developments in Business Simulation and Experiential Learning, 35, 118-127.

[15] Mariotti, C. (2008). Genre variation in academic spoken English: The case of lectures and research conference presentations. Research Centre on Languages for Specific Purposes, 1, 63-79.

[16] Mercer, N. (2010). The analysis of classroom talk: Methods and methodologies. British Journal of Educational Psychology, 80, 1-14.

[17] Mullins, G., \& Kiley, M. (2002). It's a PhD, not a Nobel Prize. How experienced examiners assess research theses. Studies in Higher Education, 27(4), 369-386.

[18] Osei Kwarteng, K., Boadi-Siaw S. Y., \& Dwarko, D. A. (2012). A history of the University of Cape Coast: Fifty years of excellence in tertiary education (1962-2012). University of Cape Coast Press, Cape Coast.

[19] Punch, K. F. (1988). Introduction to social science research: Quantitative and qualitative approaches. London: Sage Publications.

[20] Reinard, J. C. (1994). Introduction to Communication Research. USA: Brown and Benchmark.

[21] Richards, J. C. (1983). Listening Comprehension: Approach, Design, and Procedure. TESOL Quarterly, 17(2), 219-239.

[22] Rowley - Jolivet, E., \& Carter-Thomas, S. (2005). The rhetoric of conference presentation introductions: Context, argument and interaction. International Journal of Applied Linguistics, 15(1), 45-70.

[23] Sarfo, E. (2011). Variations in ways of refusing requests in English among members of a college community in Ghana. African Nebula, 3, 1-13.

[24] Swales, J. M. (1990). Genre analysis: English in Academic and Research Settings. Cambridge: Cambridge University Press.

[25] Tang, F. (2013). Instantiation of multimodal semiotic systems in science classroom discourse. Language Sciences, 37, 22-35.

[26] Tobach, M., \& Nachliebi T. (n. d). Combining theories to analyse classroom discourse: A method to study learning process. Accessed on: 1st May, 2017. Sourced form: http://www.itjsl.org/class_room_discourse.343./67\%.

[27] Wardhaugh, R. (1992). An introduction to sociolinguistics (2nd ed.). USA: Blackwell.

[28] Weisberg, B. (1993). The graduate seminars: Another research process genre. English for Specific Purposes, 12(1), 23-36.

[29] Wenger, E. (1998). Communities of practice: Learning, meaning and identity. Cambridge: Cambridge University Press. 